\title{
Study on Radio Frequency Profile of Indonesia Digital Television DVB-T2 for Urban Areas
}

\author{
Dian Fitriyani ${ }^{1}$, Khoirul Anwar ${ }^{2}$, Desti Madya Saputri ${ }^{3}$ \\ Jl. Telekomunikasi No. 1, Terusan Buah Batu, Bandung, 40257 INDONESIA \\ \{dianfitri@student. telkomuniversity.ac.id ${ }^{1}$, anwarkhoirul@ telkomuniversity.ac.id², \\ destimadyasaputri@telkomuniversity.ac.id ${ }^{3}$ \} \\ Center for Advanced Wireless Technologies (AdWiTech) ${ }^{1}$, Telkom University ${ }^{2}$
}

\begin{abstract}
The world is in the transition from Analog to Digital TV (TV), including Indonesia. Digital TV is capable of transmitting image and sound signals with sharper and clearer reception quality than Analog TV. Digital Video Terrestrial Broadcasting Second Generation (DVB-T2) is one of the Digital TV standards chosen in Indonesia because it provides services through the efficient utilization of the radio frequency spectrum in broadcasting. However, problem about the unknown parameters in DVB-T2 technology, such as the size of the Fast Fourier Transform (FFT), the length of the cyclic prefix (CP), block length, coding rate, and bandwidth are good and suitable to be applied in urban areas Indonesia. This paper studies about DVB-T2 technology performances using Orthogonal Frequency Division Multiplexing (OFDM) on DVB-T2 channels to serve various future DVB-T2 technology needs. This paper calculates and evaluates the outage performances of Indonesia DVB-T2 channels, which are also validated using bit error rate (BER) and frame error rate (FER) parameters. The simulation is based on OFDM concept in the DVBT2 standards with several cyclic prefix (CP) sizes and Binary Phase Shift Keying (BPSK) modulation. The result of this paper is an evaluation of the performance of DVB-T2 in Bandung and Jakarta that using channel coding can produce optimal parameter performance on the DVB-T2 technology. This paper uses channel coding techniques, namely simple repetition codes to evaluate and compare with not use channel coding (uncoded). For OFDM characteristics shown that can be achieved, diversity orders that can be achieved outage performances, signal-to-noise-power-ratio (SNR) values on BER performance of $10^{-4}$, the number of paths obtained and related theories. This Final Project also presents a power analysis table based on the modulation used for OFDM which is expected to help design hardware for mass production of Set Top Box (STB) receiver systems or Indonesian Digital TV aircraft.
\end{abstract}

Keywords: Digital TV DVB-T2, Radio Frequency (RF) Profile, OFDM.

\section{Introduction}

Digital transmission technology has developed and is used by almost all the world community for information and entertainment services, such as Video-On-Demand, High Devin Television (HDTV), and Mobile Television which requires wide bandwidth. DVB-T2 technology which is the second generation of Digital TV in development with the aim of increasing bit-rate, frequency efficiency, and increasing signal strength [3]. However, this DVBT2 technology is still constrained in establishing RF Profile parameters that have not been found to be applied to OFDM in Indonesian urban areas [1]. OFDM is widely used for digital 
transmission systems because of the ability of OFDM to overcome multipath fading which causes Inter-symbol interference (ISI) and Inter-channel interference (ICI) during transmission [5]. Therefore, DVB-T2 is a development of previous technology, namely DVB-T in implementing OFDM as one of the standards in the research of RF DVB-T2 profiles in Indonesian urban areas. In addition, the problem of performance in the application of the OFDM concept in the distribution of bandwidth for each DVB-T2 channel has not been found, especially for urban areas in Indonesia as shown in Table 1 [1]. In the matter of performance and bandwidth sharing of DVB-T2 technology, this research was conducted to help find proposed solutions to the problem of the OFDM RF Profile parameters. In this study, an analysis of RF Profile DVB-T2 parameters with computer simulation using NYUSIM will be analyzed. While for RF Profile parameter performance with channel coding computer simulation using MATLAB. In general, channel coding is used to improve the performance of a system by redesigning the sent signal that is affected by the effects of interference, such as noise, fading, and jamming [5]. The results of this simulation will be compared with the RF Profile simulation results using other country parameters. This future RF Profile will be used as a standard for the industrial design of making digital TV aircraft in the Indonesian urban area STB DVB-T2. In this paper, we consider NYUSIM using statistical spatial channel model (SSCM) technique to model the channel from measurements. SSCM is considered in this paper since SSCM measures the channel with a large number of samples and analyzes statistically by taking into account the spatial characteristic of the environment including types of the antenna [6]. $\mathrm{n}$ trend then used the name technical indicator. Technical indicators related to the stock movement chart. The main component of the formation of the stock movement chart consists of 5 component of price is open, high, low, close, and volume of transactions.

Table 1. Indonesia does not yet have a DVB-T2 profile [1].

D.2 Indonesia

N/A

D.3 Malaysia

Malaysia Mode

\begin{tabular}{|c|c|c|c|c|}
\hline Identifier & MS 1 & MS 2 & MS 3 & MS 4 \\
\hline \multicolumn{5}{|l|}{ Overall } \\
\hline FFT Size & $32 \mathrm{~K}$ & $32 \mathrm{~K}$ & $32 \mathrm{~K}$ & $32 \mathrm{~K}$ \\
\hline GI & $1 / 8$ & $19 / 256$ & $1 / 128$ & $1 / 8$ \\
\hline SISO/MISO & SISO & SISO & SISO & SISO \\
\hline PAPR & TR & TR & TR & TR \\
\hline Bandwidth & $8 \mathrm{Mhz}$ & $8 \mathrm{Mhz}$ & $8 \mathrm{Mhz}$ & $7 \mathrm{Mhz}$ \\
\hline Carrier Mode & Extended & Extended & Extended & Normal \\
\hline Pilot Pattern & PP2 & PP4 & PP7 & PP2 \\
\hline L1 Modulation & 64 QAM & 64 QAM & 64 QAM & 64 QAM \\
\hline $\begin{array}{l}\text { Data Symbols per Frame } \\
\text { (Ldata) }\end{array}$ & 43 & 61 & 59 & 43 \\
\hline OFDM Symbols per Frame (Lf) & 44 & 62 & 60 & 44 \\
\hline Frame Duration & 178 & 239 & 217 & 203 \\
\hline Frames per SuperFrame & 2 & 2 & 2 & 2 \\
\hline
\end{tabular}




\section{System Model}

We consider the bandwidth of $10 \mathrm{MHz}$ for the frequency of $694 \mathrm{MHz}$ which is standard regulation from KemKominfo Indonesia Digital Television DVB-T2 [1]. In this paper, the channel model with parameter conditions urban environment in Indonesia. In this Final Project environmental parameters the city of Bandung and the city of Jakarta used to be a representation of the region urban areas in Indonesia for initial studies [9]. Barometric pressure, humidity, rain rate and temperature in Bandung and Jakarta are used as climate parameters input [10]. This model can represent an urban microcell environment due to the real environment of Bandung and Jakarta city with high population density. We set 200 meters as a distance between the transmitter and the receiver. Furthermore, we define the environment as NLOS due to building and foliage. We perform computer simulations based on NYUSIM simulator using environmental parameters of Bandung and Jakarta city, shown in Table II and Table III, to generate power delay profile (PDP) [5], [6] representing the average power and delay associated with a given multipath delay samples [11]. We use orthogonal frequency division multiplexing with cyclic prefix (CP-OFDM) system to confirm the performance of the obtained channel model, where the block diagram is shown in

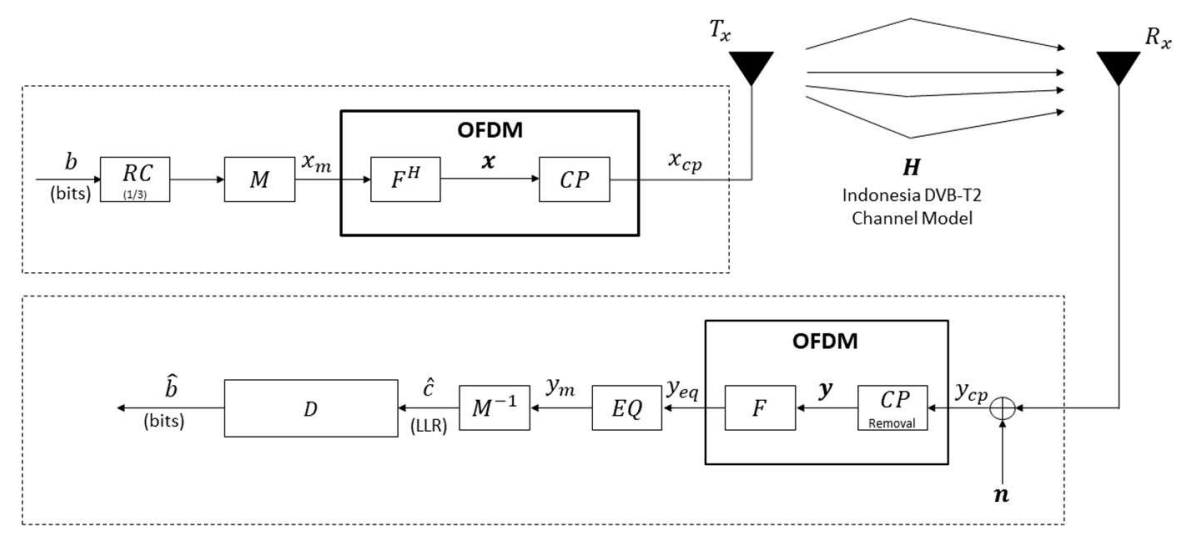

Figure 1. The considered structure of CP-OFDM with simple channel coding to confirm the theoretical outage performance of RF Profile DVB-T2 Indonesia.

Coding rate for uncoded $R=1$ and for Repetition codes $R=1 / 3, B$ bits of information are generated at the transmitter side randomly as many as a certain number of bits with the same probability of occurrence of 0 and 1 bits. $M$ is the modulation block which is Binary phase shift keying (BPSK) modulator. After being generated, the information will be mapped and modulated on the modulator $M$ to produce an $x_{m}$ symbol containing bits of information. The modulated BPSK symbols are then transformed using Inverse Fast Fourier Transform (IFFT) $F^{H}$ with block-length of 128 . CP module adds cyclic prefix (CP) with a length the same as the number of the paths. OFDM symbols are then transmitted over multipath fading channel. We use Bandung and Jakarta city channel model as the multipath channel $H$. At the receiver noise is added following Gaussian distribution. $C P$ - removal module removes the $C P$ from the received block. We perform fast Fourier transform (FFT) $F$ prior to equalization 
module $E Q$. We then perform demodulation $M^{-1}$ of BPSK. Repetition decoding is then applied a decoder to decode the received bit.

\section{The Proposed Urban RF Profile of DVB-T2 Indonesia}

\subsection{Channel Capacity}

The channel capacity of $\mathrm{C}$ is the maximum value of mutual information of the total information sent and received, where the error probability approaches zero when condition coding rate $\mathrm{R}$ in under $\mathrm{C}$ [14]. Calculation of channel capacity is important in designing $\mathrm{RF}$ Profile urban areas. This channel capacity limit determines the maximum data speed data rates that can be achieved without the existence of delay or complexity of the interference of the encoder or decoder. Channel capacity is influenced by the width of the transmission bandwidth and PDP. The calculation of channel capacity is also based on the Shannon Capacity theorem.

$$
C=B \cdot \log _{2}(1+\gamma),
$$

where $C$ is channel capacity, $B$ is bandwidth in Hertz units, and $\gamma$ is a ratio of signal power to the noise power (SNR).

\subsection{Channel Models}

To obtain a representative channel model, we conduct a series of computer simulations to calculate the CDF over 1000 channel realizations, of which the result is shown in Fig. 3. The obtained representative PDP of Bandung and Jakarta City has 8 paths with normalized powers. This PDP is obtained by selecting only the path having power beyond $-140 \mathrm{dBm}$. Other powers below $-140 \mathrm{dBm}$ are assumed as noise [13]. It is important to note here that the delay of each path is about $100 \mathrm{~ns}$ from the preceding path.

\subsection{Outage Performances}

Outage Performances is the collection of outage probability that is needed in the design of a RF Profile DVB-T2 to maximize the performance of a designed RF Profile. Outage Performances of urban areas Jakarta and Bandung city is shown is Fig. 2. 


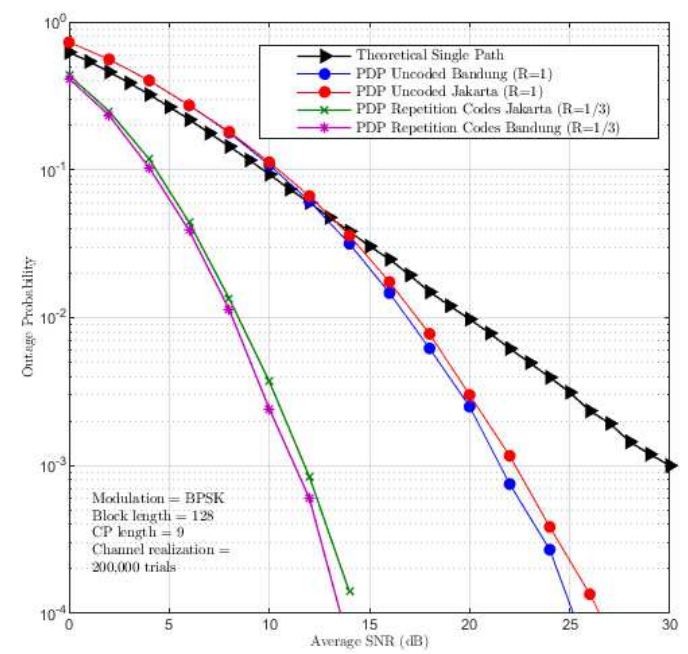

Figure 2. Outage Performance for Bandung and Jakarta City Uncoded and Repetition Codes.

Based on curve outage performance that is obtained by MATLAB simulation, multipath has better perfomance than single path.

In addition, information on Outage Performances is useful for improving power efficiency by regulating transmit power to follow the outage performances curve for each desired capacity and probability. Outage probability $P_{\text {otg }}$ is a probability of $P_{r}$ when the $C$ capacity falls below coding rate $R$ which results in information not being transmitted [15]. Outage probability is calculated by

$$
P_{o t g}=P_{r}(R>C)
$$

As long as $R \leq C$, the transmitted information can be decoded maximally on the receiver side. PDP produced by NYUSIM Channel Simulator is used in calculating channels capacity of urban areas RF Profile DVB-T2. The channel capacity $C$ in the multipath fading channel is expressed with

$$
C=\left(\frac{B}{F}\right) \cdot \sum_{n=1}^{F} \log _{2}\left(1+\left(\left|\psi_{n}\right|^{2} \cdot \gamma\right)\right),
$$

where $F$ is the block length of a frame that is transmitted. The $\psi_{n}$ symbol represents the eigenvalue of the multipath channel obtained from the result of representative PDP.

Table 2. NYUSIM channel simulator Parameter Input for Bandung Area [10-12]. 


\begin{tabular}{cc}
\hline \multicolumn{2}{c}{ NYUSIM INPUT } \\
\hline Frequency & $694 \mathrm{MHz}$ \\
RF Bandwidth & $10 \mathrm{MHz}$ \\
Scenario & Umi \\
Environment & NLOS \\
T-R Separation - Lower Bound & 200 \\
Upper Bound & 200 \\
TX Power & $30 \mathrm{dBm}$ \\
Number of RX & 1000 \\
Baromatric Pressure & 1009.4 \\
Humidity & $67 \%$ \\
Temperature & $28 \mathrm{C}$ \\
Rain rate & $120 \mathrm{~mm} / \mathrm{h}$ \\
Polarization & $\mathrm{Co}-\mathrm{Pol}$ \\
Foliage Loss & $\mathrm{No}$ \\
Follage Attenetion & $\mathrm{No}$ \\
\hline
\end{tabular}

Table 3. NYUSIM channel simulator Parameter Input for Jakarta Area [10-12].

\begin{tabular}{cc}
\hline \multicolumn{2}{c}{ NYUSIM INPUT } \\
\hline Frequency & $694 \mathrm{MHz}$ \\
RF Bandwidth & $10 \mathrm{MHz}$ \\
Scenario & Umi \\
Environment & NLOS \\
T-R Separation - Lower Bound & 200 \\
Upper Bound & 200 \\
TX Power & $30 \mathrm{dBm}$ \\
Number of RX & 1000 \\
Baromatric Pressure & 1009.5 \\
Humidity & $54 \%$ \\
Temperature & $33 \mathrm{C}$ \\
Rain rate & $120.4 \mathrm{~mm} / \mathrm{h}$ \\
Polarization & $\mathrm{Co}-\mathrm{Pol}$ \\
Foliage Loss & $\mathrm{No}$ \\
Follage Attenetion & $\mathrm{No}$ \\
\hline
\end{tabular}

\subsection{Representative PDP}

In this paper NYUSIM channel simulator produced Instantaneous PDP with 1000 trials to obtain one representative PDP of urban area. Figure 3 shows Representative PDP for Bandung and Jakarta City. $\Delta T$ is propagation delay where is obtained by

$$
\Delta T=\frac{1}{\Delta f}
$$


where $\Delta f$ is bandwidth sampling for simulation. However, in this paper to obtain the $\Delta f$ we use Nyquist Theory where $\Delta f=2 \times B W$ transmission.
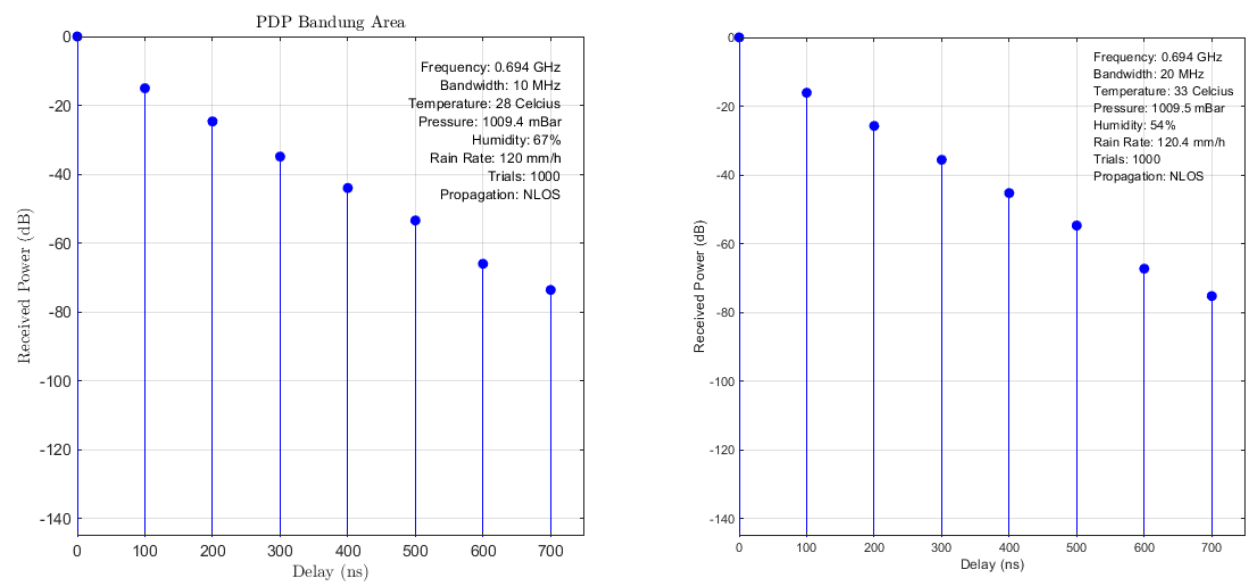

Figure 3. PDP in Bandung City and Jakarta City.

\section{Performances Evaluation of Indonesia DVB-T2 Channel Model}

\subsection{BER Perfoemances}

This paper validates the proposed channel model digital TV DVB-T2 for urban areas by calculating Bit Error Rate (BER). Calculation BER in this paper used 200,000 experiments. This paper also evaluated BER performances by comparing BER performance on a channel Rayleigh fading with BER performance on a RF Profile DVB-T2. Performance on channel Rayleigh fading is the worst performance compared to performance on channel Rician Fading, and AWGN. Therefore, the performance evaluation in this paper is by comparing BER performances in a RF Profile DVB-T2 with BER performances on Rayleigh fading [9]. Calculation of BER in Rayleigh Fading with BPSK modulation is expressed by

$$
B E R_{(B P S K-\text { Fading })}=\frac{1}{2}\left[1-\frac{1}{\sqrt{1+\frac{1}{\gamma}}}\right],
$$

Where $\gamma$ is signal-to-noise-ratio (SNR). The performance of BER on the urban areas is shown in Fig. 4. RF Profile without channel coding (Uncoded) with code rate $R=1$ in Jakarta and Bandung City achieve BER performances $10^{-4}$ at $\gamma=34 \mathrm{~dB}$ and $\gamma=33.5 \mathrm{~dB}$. The performance of BER on the urban areas RF Profile with channel coding Repetition codes with code rate $R=1 / 3$ in Jakarta and Bandung City achieve BER performances $10^{-4}$ at $\gamma=14 \mathrm{~dB}$ and $\gamma=14.02 \mathrm{~dB}$. We found that the BER performances with Repetition codes DVB-T2 has better performance due to the multipath fading effect of the proposed DVB-T2 channel model. The BER performance obtained has the same gradient as the BER performance theory on 
Rayleigh fading channels. In addition, the BER performance with BPSK modulation has a high power gain. This shows that the high level of modulation used, the power consumption of power consumption will be more efficient in the system with the modulation level. This paper also presents power analysis in SNR on BER performance [7].

\subsection{FER Perfoemances}

This section validates the proposed Channel Model Digital TV DVB-T2 by calculating Frame Error Rate (FER) obtained by

$$
F E R=\frac{\text { Frame }_{\text {error }}}{\text { Frame }_{\text {transmitted }}}
$$

We use CP-OFDM system with BPSK modulation to validate theoretical outage performanceat $R=1$ where are shown in Fig. 5, where the outage performance curve for BPSK with coding rate $R=1$ for Uncoded and $R=1 / 3$ for Coded with Repetition codes. Outage probability for Bandung and Jakarta City with $R=1$ of $10^{-4}$ is achieve at SNR $\gamma=25 \mathrm{~dB}$ and SNR $\gamma=25.5 \mathrm{~dB}$. These curve are then used as the baseline comparison for practical FER performances. Figure 5 shows Bandung and Jakarta Uncoded achieve FER performance $10^{-2}$ at SNR $\gamma=33 \mathrm{~dB}$ and SNR $\gamma=33.2 \mathrm{~dB}$. FER Performances for Bandung and Jakarta City with $R=1 / 3$ of $10^{-2}$ is achieve at SNR $\gamma=12.5 \mathrm{~dB}$ and SNR $\gamma=13 \mathrm{~dB}$

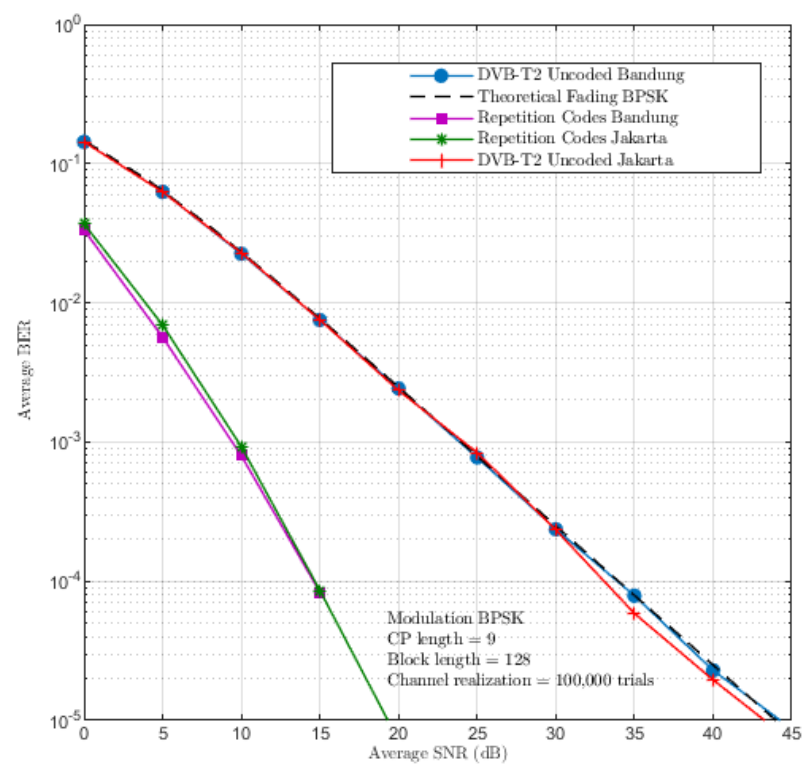

Fig 4. BER Performances for Bandung and Jakarta City. 


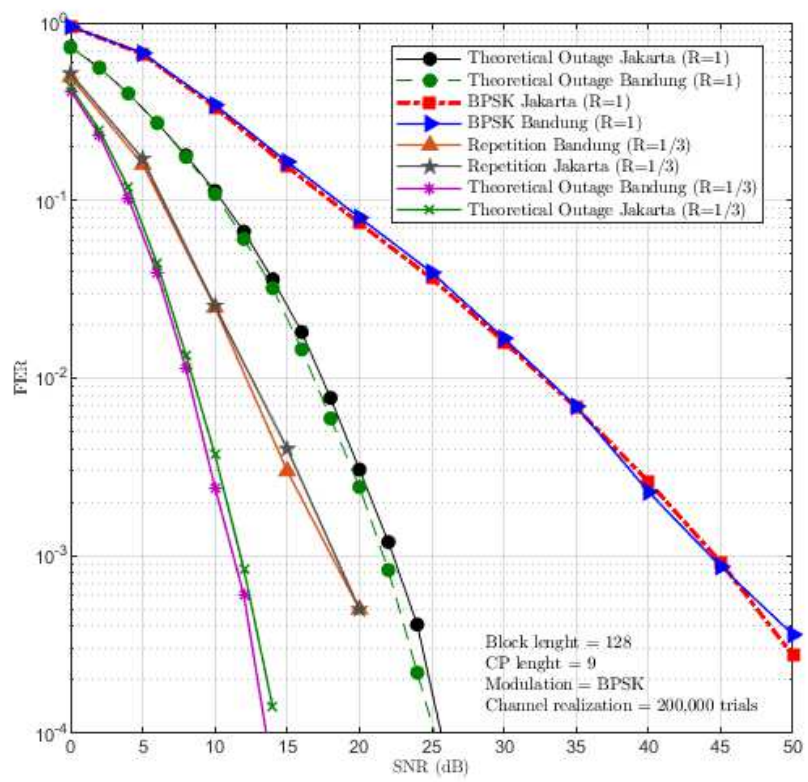

Figure 5. FER Performances for Bandung and Jakarta City.

\section{Conclusion}

This paper has studies of OFDM from RF Profile DVB-T2 Indonesia to evaluate and obtain performance in accordance with the environment of Indonesian urban areas. Channel modeling conducted with NYUSIM as a channel simulator to produces a PDP representative representing urban area channels based on environmental parameters of the Bandung and Jakarta City. such as air pressure, humidity, temperature, rainfall, and leaves that represent the natural conditions of urban areas in Indonesia. The DVB-T2 channel model in Bandung has 8 paths with mean excess delay and RMS delay spread of 3,810 ns and $21.36 \mathrm{~ns}$. The DVB-T2 channel model in Jakarta has 8 paths with mean excess delay and RMS delay spread of 2,93 ns and 18,86 ns. Outage performances obtained are expected to be a reference from OFDM for the city of Bandung and Jakarta. Outage performances validation of DVB-T2 channels for the cities of Bandung and Jakarta were confirmed using the CP-OFDM system without channel coding (uncoded) compared to using channel coding Repetition Codes. The Outage performances with $R=1$ at $10^{-4}$ in Bandung an Jakarta City is obtained when $S N R=25 \mathrm{~dB}$ and $S N R=25.5 \mathrm{~dB}$ , and with channel coding is obtained when $S N R=14 \mathrm{~dB}$ and $S N R=14.5 \mathrm{~dB}$, are meaning that diversity of order 3 can be achieved. Performance at BER Bandung City and Jakarta City $10^{-4}$ is obtained when the SNR is $34 \mathrm{~dB}$ and SNR is $33.5 \mathrm{~dB}$. In BER performance in Bandung and Jakarta City with Repetition codes $R=1 / 3$ obtained when $S N R=14.8 \mathrm{~dB}$ and $S N R=$ $14.9 \mathrm{~dB}$. FER performances of $10^{-2}$ from DVB-T2 Digital TV Uncoded with $R=1$ in Bandung and Jakarta City is achieved with $S N R=33 \mathrm{~dB}$ and $S N R=33.2 \mathrm{~dB}$. FER performances of $10^{-2}$ from DVB-T2 Digital TV with Channel Coding $R=1 / 3$ Bandung and 
Jakarta City is achieved with $S N R=12 \mathrm{~dB}$ and $S N R=12.2 \mathrm{~dB}$. Outage performances that has been derived from the channel being modeled shows that DVB-T2 channel performances can be improved by using channel coding Repetition Codes. The FER performances of the DVBT2 can be approach the Outage Probability curve when the system uses channel coding. The use of channel coding with high coding rate $R=1 / 3$ can improve performances. In addition, based on the practical parameters of BER and FER DVB-T2 that use channel coding to increase the efficiency of power consumption. The results of channel modeling in this paper are expected to be used as references in channel modeling experiments in Indonesian urban areas by using devices such as channel sounders and Universal Software Radio Peripheral (USRP). In addition, the proposed DVB-T2 channel can be used as a references for the manufacture of STB devices and the implementation of DVB-T2 channels for the Television devices industry.

\section{References}

[1] E. K. Anwar and M. Eng, "Implementing TV Digital DVB-T2 Indonesia Introduction to Digital TV Indonesia," no. 1, pp. 1-15, Oct, 2018

[2] 3GPP, "Technical spesification group radio access network; NR, multiplexing and channel coding," 3GPP, Tech. Rep., December 2017

[3] DVB-T2 Integrated Receiver Decoder Technical Specification for ASEAN Date : June 2014," vol. 42 . June, 2014

[4] A. F. Molisch, WIRELESS COMMUNICATIONS, 2nd ed. India: Wiley Publishing, 2011

[5] D. W. Astuti, "Analisa Simulasi Performansi Penggunaan Orthogonal Frequency Division Multiplexing Pada Sistem Digital Video Broadcasting-Terrestrial.” J. Telekomun. dan Komput., vol. 3, no. 1 , p. 65,2017

[6] N. Suwansukho and S. Promwong, "Experimental study of DVB-T2 in Thailand," 20th Int. Comput. Sci. Eng. Conf. Smart Ubiquitos Comput. Knowledge, ICSEC 2016, pp. 7-12. Dec, 2017

[7] M. Alfaroby, N. M. Adriansyah, and K. Anwar, "Study on channel model for Indonesia 5G networks," in 2018 International Conference on Signals and Systems (ICSigSys), May 2018, pp. 125130

[8] E. Christy, R. P. Astuti, and K. Anwar, "5G Channel Models Under Foliage Effect and Their Performance Evaluations," in International Conference on ICT for Rural Development (ICT-RuDev), Oct. 2018

[9] K. P. Atmaja, A. Khoirul, "Study on OFDM Numerology 4 of 5G New Radio (NR) under Indonesia 5G Channel Model", in 2018 2nd Symposium of Future Telecommunication and Technologies (SOFTT), Nov 2018

[10] www.kominfo.go.id/content/detail/13655/, "KOMINFO siapkan aturan standarisasi perangkat Telekomunikasi untuk penyiaran,” July 2018

[11] RI, MENKOMINFO, Permen No. 9 Tahun 2014 Persyaratan Teknis Alat dan Perangkat Penerima Televisi Siaran Digital Berbasis Standar Digital Video Broadcasting Terrestrial Second Generation," 2014

[12] S. Joko, T. Kenji, I. Mitsuyoshi, Study of Prediction Models Compared with the Measurement Results of Rainfall Rate and Ku-band Rain Attenuation at Indonesian Tropical Cities. IEEE, CICS.2005.1689325, 2015

[13] S. Sun, G. R. MacCartney and T. S. Rappaport, "A novel millimeter-wave channel simulator and applications for 5G wireless communications," 2017 IEEE International Conference on Communications (ICC), Paris, 2017, pp. 1-7

[14] M. N. Rahman and K. Anwar, "Outage Performance of 5G Channel Model Considering Temperature Effects at $28 \mathrm{Ghz}$," in 2nd International Symposium on Future Telecommunication Technologies (SOFFT), Bandung, Dec, 2018 
[15] R. D. Wahyuningrum and K. Anwar, "Outage Performance of 5G Channel Model Considering Humidity Effects at $28 \mathrm{Ghz}$,"in 2nd International Symposium on Future Telecommunication Technologies (SOFFT), Bandung, Oct, 2018. 